\title{
Internal carotid artery stent fracture likely caused by hyoid bone compression
}

\author{
Ahmet Arif Yalçın', Ahmet Güner', Ünal Aydın², Çağdaş Topel ${ }^{3}$ \\ 'Department of Cardiology, Mehmet Akif Ersoy Thoracic and Cardiovascular Surgery Training and Research Hospital, Istanbul, Turkey \\ 2Department of Cardiovascular Surgery, Mehmet Akif Ersoy Thoracic and Cardiovascular Surgery Training and Research Hospital, Istanbul, Turkey \\ ${ }^{3}$ Department of Radiology, Mehmet Akif Ersoy Thoracic and Cardiovascular Surgery Training and Research Hospital, Istanbul, Turkey
}

\author{
Correspondence to: \\ Ahmet Güner, MD, \\ Department of Cardiology, \\ Mehmet Akif Ersoy Thoracic \\ and Cardiovascular Surgery \\ Training and Research \\ Hospital, \\ Turgut Özal Bulvari No. 11, \\ 34303, Kucukcekmece, \\ Istanbul, Turkey, \\ phone: +90 50565333 35, \\ e-mail: \\ ahmetguner489@gmail.com \\ Copyright by the Author(s), \\ 2021 \\ Kardiol Pol. 2021: \\ 79 (9): 1036-1037. \\ DOI: 10.33963/KP.a22021.0044 \\ Received: \\ February 12, 2021 \\ Revision accepted: \\ June 20, 2021 \\ Published online: \\ June 22, 2021
}

A 70-year-old male patient visited the clinic for a regular check-up. Targeted medical history included a history of carotid artery stenting (CAS) (Xact carotid stent, Abbott Vascular, Lake Bluff, IL, USA) (Figure 1A). The carotid intervention was not complicated by dissection, oversized stent, or stent fracture. A routine Duplex ultrasonography follow-up indicated that the patient had the right internal carotid artery (ICA) asymptomatic restenosis (peak systolic velocity [PSV]: $360 \mathrm{~cm} / \mathrm{s}, \mathrm{ICA} / \mathrm{common}$ carotid artery [CCA] PSV ratio $>4.15$ ). Residual, mixed plaque without calcification was present outside the stent. Computed tomography angiography (CTA) demonstrated a fractured right ICA stent (Figure 1B-C). Notably, it showed that the tip of the greater horn of the hyoid bone $(\mathrm{HoB})$ passes between the right ICA and the right external carotid artery. A three-dimensional image reconstruction of CTA indicated that the right ICA traverses between the greater horn of the $\mathrm{HoB}$ and the transverse process of the $\mathrm{C} 4$ vertebra. The fractured stent was compressed by the $\mathrm{HoB}$ at its origin (Figure 1D). In contrast, the left carotid bifurcation and ICA were lateral to the HoB. Moreover, CTA did not show tortuosity and calcification in the right ICA. Cinefluoroscopic examination indicated a type-4 stent fracture (i.e., a complete transverse linear fracture with stent displacement) [1] in the right ICA (Figure $1 \mathrm{E})$. Surgery was recommended because ICA stenosis due to extrinsic compression was contraindicated for endovascular therapy. Hence, the patient was scheduled for right carotid endarterectomy under general anesthesia. Vascular structures were clamped after intravenous injection of 5000 units of unfractionated heparin. The carotid endarterectomy was performed (Figure 1F). A fractured and thrombosed stent was revealed and excised (Supplementary material, Figure S1), and the reconstruction of the right ICA segment required a poly-patch use. The patient was discharged on the $6^{\text {th }}$ day without any adverse clinical events. At the $20^{\text {th }}$-month follow-up, Duplex ultrasonography showed normal findings (right ICA PSV $<125 \mathrm{~cm} / \mathrm{s}$, right ICA/CCA PSV <2).

Anatomically, the carotid arteries are located in a fibrous layer on the neck, which allows them to follow muscle movements properly [1]. The elongation and excessive tortuosity of the ICA can change the vessel route in this layer, causing it to be close to the HoB and consequently undergo mechanical stress [2]. Mechanical stress of the carotid artery by bone structures - $\mathrm{HoB}-$ is an extremely rare clinical entity. Three factors must take place to cause this mechanical pressure: (1) a long HoB horn protruding dorsally from the larynx; (2) a lower level of separation of the ICA from CCA; (3) kinking of ICA, which tends to deform stents placed in the vascular structure $[3,4]$. Moreover, this mechanical compression can cause endothelial damage and consequently atheromatous plaque formation and thromboembolic events. Previously, Mori et al. [5] reported an ischemic cerebrovascular event with the occlusion and recanalization of a non-atherothrombotic ICA due to HoB compression. Extrinsic compression of the carotid artery was the contraindication to the endovascular treatment of ICA stenosis. Hence, two main treatment options can be considered in this pathology: (1) hyoid bone resection plus re-CAS [4]; (2) carotid endarterectomy, which includes removing surgically the fractured stent and then closing it with the poly-patch. 


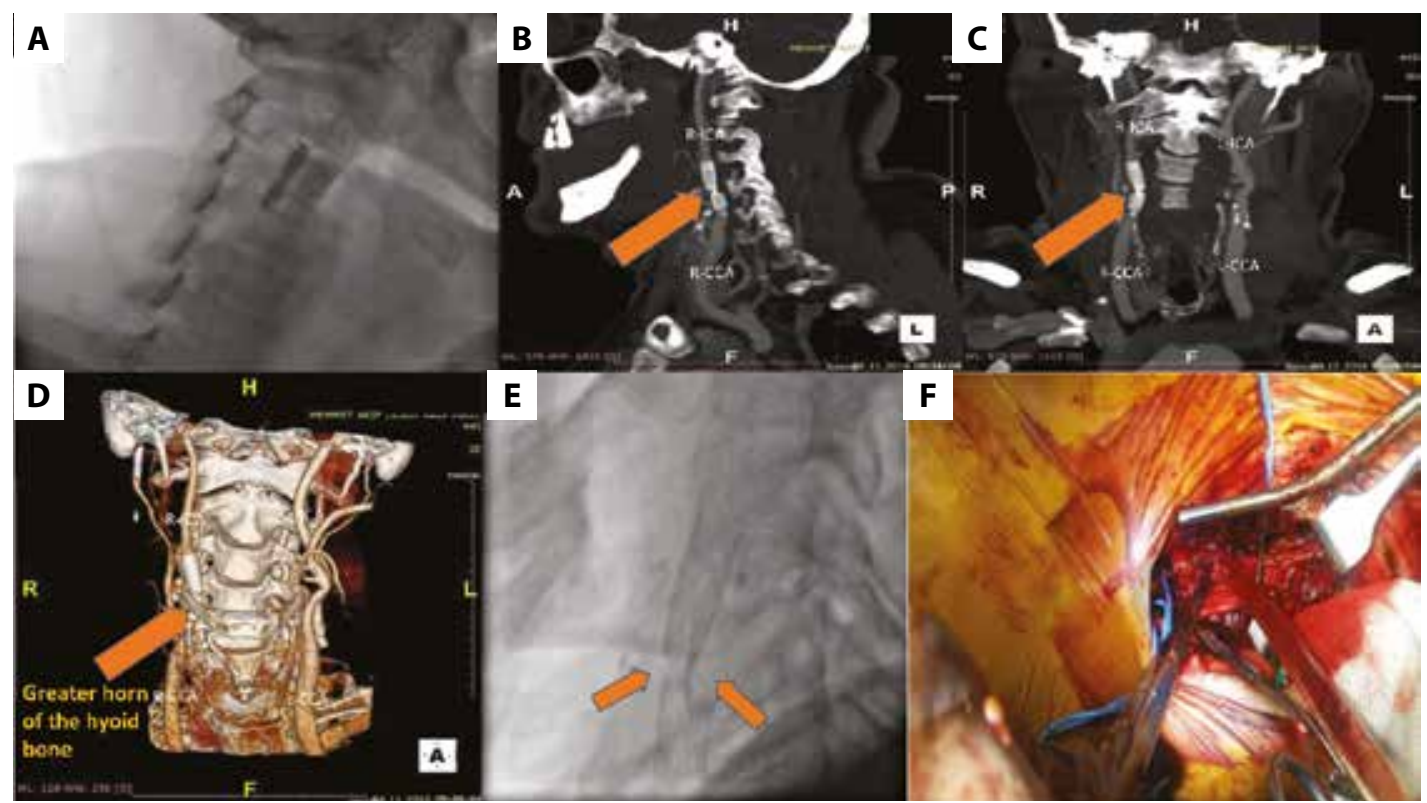

Figure 1. A. Conventional carotid angiography shows an $80 \%-90 \%$ stenotic lesion in the right internal carotid artery and successful stent implantation. B. and C. Coronal and sagittal images show the fractured right internal carotid stent. The tip of the greater horn of the hyoid bone passes between the right internal carotid artery and right external carotid artery (arrowhead). D. The three-dimensional image shows the medialized right internal carotid artery, traversing between the greater horn of the hyoid bone and the transverse process of the $\mathrm{C} 4$ vertebra (the red arrow points at that the greater horn of hyoid bone between external and internal carotid arteries). The left carotid bifurcation and internal carotid artery pass laterally to the hyoid bone (arrowhead). E. Cinefluoroscopic image indicates the fracture of the right internal carotid artery stent (arrowheads). F. The intraoperative image indicates that the internal carotid artery was explored

Abbreviations: L-CCA, left common carotid artery; L-ICA, left internal carotid artery; R-CCA, right common carotid artery; R-ICA, right internal carotid artery

\section{Supplementary material}

Supplementary material is available at https://journals. viamedica.pl/kardiologia_polska.

\section{Article information}

Conflict of interest: None declared.

Open access: This article is available in open access under Creative Common Attribution-Non-Commercial-No Derivatives 4.0 International (CC BY-NC-ND 4.0) license, allowing to download articles and share them with others as long as they credit the authors and the publisher, but without permission to change them in any way or use them commercially. For commercial use, please contact the journal office at kardiologiapolska@ptkardio.pl.

How to cite: Yalçın AA, Güner A, Aydın Ü, Topel Ç. Acute coronary syndrome due to extrinsic left main compression. Kardiol Pol. 2021; 79(9): 1036-1037, doi: 10.33963/KP.a2021.0044.

\section{REFERENCES}

1. Sfyroeras GS, Koutsiaris A, Karathanos C, et al. Clinical relevance and treatment of carotid stent fractures. J Vasc Surg. 2010; 51(5): 1280-1285, doi: 10.1016/j.jvs.2010.01.050, indexed in Pubmed: 20347546.

2. Gray H. Anatomy of the Human Body. $39^{\text {th }}$ edition. Churchill Livingstone, London 2000.

3. Martinelli O, Fresilli M, Jabbour J, et al. Internal carotid stenosis associated with compression by hyoid bone. Ann Vasc Surg. 2019; 58:379.e1-379.e3, doi: 10.1016/j.avsg.2018.09.043, indexed in Pubmed: 30684622.

4. Tekieli Ł, Musiałek P, Kabłak-Ziembicka A, et al. Severe, recurrent in-stent carotid restenosis: endovascular approach, risk factors. Results from a prospective academic registry of 2637 consecutive carotid artery stenting procedures (TARGET-CAS). Postępy Kardiol Interwencyjnej. 2019; 15(4): 465-471, doi: 10.5114/aic.2019.90221, indexed in Pubmed: 31933663.

5. Mori M, Yamamoto H, Koga M, et al. Hyoid bone compression-induced repetitive occlusion and recanalization of the internal carotid artery in a patient with ipsilateral brain and retinal ischemia. Arch Neurol. 2011; 68(2): 258-259, doi: 10.1001/archneurol.2010.371, indexed in Pubmed: 21320995. 